\title{
Correction: The pathophysiological impact of stress on the dopamine system is dependent on the state of the critical period of vulnerability
}

\author{
Felipe V. Gomes ${ }^{1,2} \cdot$ Xiyu Zhu ${ }^{1}$. Anthony A. Grace ${ }^{1}$
}

Published online: 27 September 2019

c) Springer Nature Limited 2019

\section{Correction to: Molecular Psychiatry}

https://doi.org/10.1038/s41380-019-0514-1

published online 05 September 2019

In the original version of this article, one of the images within Fig. 2 was inadvertently misplaced. The repre- sentative image of the combined 'PV/PNN' for the stress group 'PD51' was accidentally also included as the representative image of the combined 'PV/PNN' for the stress group 'PD75'. This has been corrected in both the PDF and HTML versions of the article. The original incorrect version of Fig. 2 is displayed below.
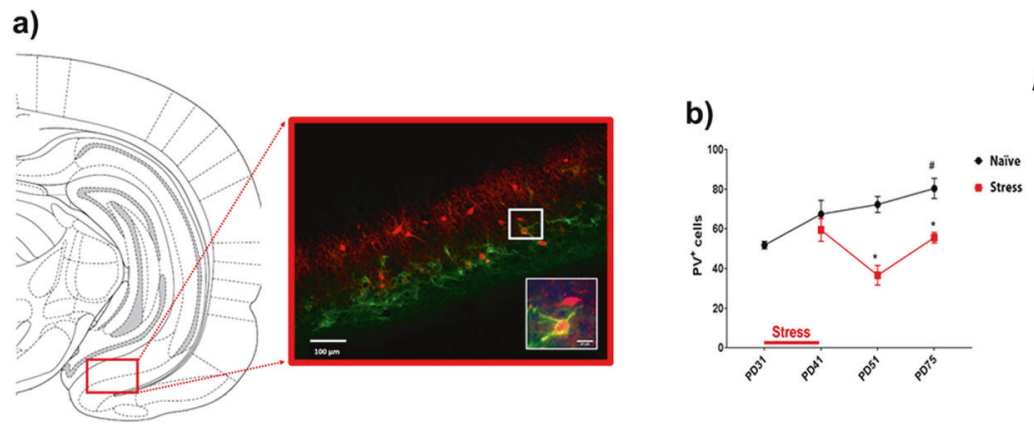

\section{Adolescent stress}
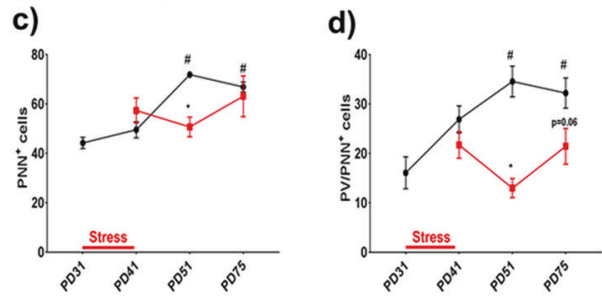

e) Naïve Stress

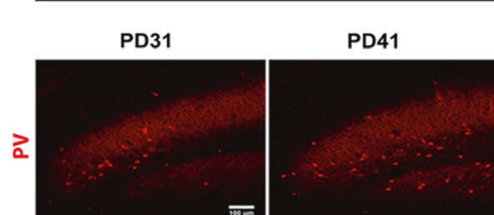
PD51
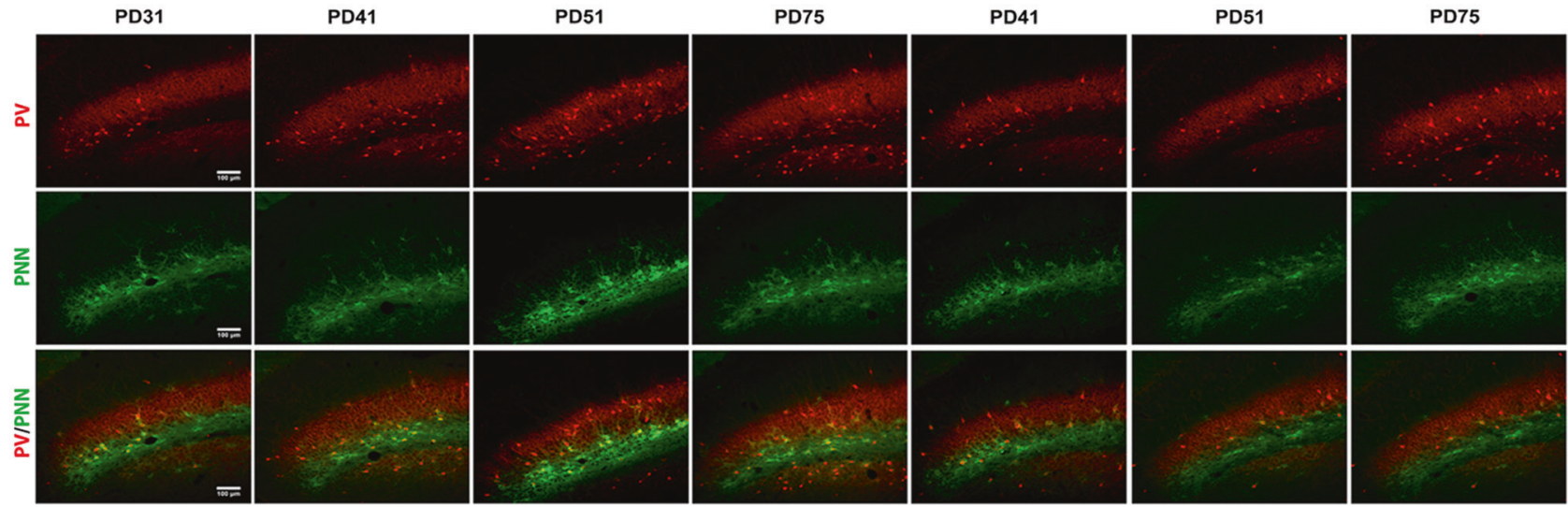

Felipe V. Gomes gomesfv@usp.br

1 Departments of Neuroscience, Psychiatry and Psychology, University of Pittsburgh, Pittsburgh, PA, USA
2 Department of Pharmacology, Ribeirao Preto Medical School, University of Sao Paulo, Ribeirao Preto, SP, Brazil 